UDC 631.4(479.24)

LBC 40.341.4(5Азе)

\title{
SOIL-ECOLOGICAL FEATURES OF GRAY-BROWN (CHESTNUT) SOILS FORMED ON THE NORTH-EASTERN SLOPE OF THE LESSER CAUCASUS (WITHIN THE SHAMKIRCHAY RESERVOIR BASIN)
}

\author{
Ramil Sadigov \\ Azerbaijan State Oil and Industry University, Baku, Republic of Azerbaijan
}

\begin{abstract}
On the north-eastern slope of the Lesser Caucasus, within the boundaries of Shamkir administrative district, the most common soils in the Shamkirchay reservoir basin are gray-brown (chestnut) soils. Since the commissioning of the reservoir, these lands have been intensively used as new irrigated areas under agricultural production. To some extent, non-compliance with planting norms when using irrigation can lead to a decrease in soil fertility parameters, soil degradation, and an increased risk of salinization.

The main purpose of the study is to analyze the current state of the main physicochemical and fertility indicators of soils in the basin and the relationship between them in the gray-brown (chestnut) soils spread within the basin boundaries of the reservoir. Diagnostic indicators, agrochemical properties and results of their analysis of soil plots placed in characteristic places were analyzed in tables and explanations. The main indicators are humus, total nitrogen, phosphorus and potassium, granulometric composition (sand, dust, silt and clay fractions), soil environmental reaction $(\mathrm{pH})$ and carbonate content $\left(\mathrm{CaCO}_{3}\right)$, statistical analysis. The article has covered studies in dark, conventional and light gray-brown (semi-brown) semi-soils in three sub-areas of gray-brown (chestnut) soils, mainly distributed in the Shamkirchay reservoir. In each of the three subclasses, profiles are set in specific locations. The practical part has been implemented in 2 stages. During the field studies, 9 profiles have been excavated, relevant samples have been taken, and analysis has been performed to determine the diagnostic performance. The results of the analyses have been presented in the respective tables and have been analyzed in detail. All analyses have been carried out on the basis of modern methods.

Key words: agroecological assessment, ordinary gray-brown soil, dark gray-brown soil, light gray-brown soil, fertility parameters, granulometric composition, diagnostic indicator, soil profile.

Citation. Sadigov R. Soil-Ecological Features of Gray-Brown (Chestnut) Soils Formed on the North-Eastern Slope of the Lesser Caucasus (Within the Shamkirchay Reservoir Basin). Natural Systems and Resources, 2020, vol. 10, no. 3, pp. 27-33. DOI: https://doi.org/10.15688/nsr.jvolsu.2020.3.4
\end{abstract}

УДК 631.4(479.24)

ББК 40.341.4(5Азе)

\section{ПОЧВЕННО-ЭКОЛОГИЧЕСКИЕ ОСОБЕННОСТИ СЕРЫХ (КАШТАНОВЫХ) ПОЧВ, ОБРАЗОВАННЫХ НА СЕВЕРО-ВОСТОЧНОМ СКЛОНЕ МАЛОГО КАВКАЗА (В ПРЕДЕЛАХ ШАМКИРЧАЙСКОГО БАССЕЙНА)

\author{
Рамиль Садыгов
}

Азербайджанский государственный нефтяной и промышленный университет, г. Баку, Республика Азербайджан 


\section{РЕСУРСОВЕДЕНИЕ}

Аннотация. На северо-восточном склоне Малого Кавказа, в границах Шамкирского административного района, наиболее распространенными почвами в бассейне Шамкирчайского водохранилища являются серо-коричневые (каштановые) почвы. После ввода в эксплуатацию водохранилища эти земли интенсивно использовались в качестве новых орошаемых площадей под сельскохозяйственным производством. В некоторой степени несоблюдение норм посадки при использовании орошения может привести к снижению параметров плодородия почвы, деградации почвы и повышенному риску засоления.

Основной целью исследования является анализ современного состояния основных физико-химических показателей и показателей плодородия почв в бассейне и взаимосвязи между ними в серо-коричневых (каштановых) почвах, распространенных в пределах границ бассейна водохранилища. Диагностические показатели, агрохимические свойства и результаты их анализа почвенных участков, размещенных в характерных местах, анализировались в таблицах и пояснениях. Основными показателями являются гумус, общий азот, фосфор и калий, гранулометрический состав (фракции песка, пыли, ила и глины), реакция окружающей среды почвы $(\mathrm{pH})$ и содержание карбонатов $\left(\mathrm{CaCO}_{3}\right)$, статистический анализ.

В статье освещены исследования на темных, обычных и светло-серо-коричневых (полугорелых) полупочвах в трех подобластях серо-коричневых (каштановых) почв, в основном распределенных в Шамкирчайском водохранилище. В каждом из трех подклассов профили устанавливаются в определенных местах. Практическая часть была реализована в 2 этапа. В ходе полевых исследований было выкопано 9 профилей, были отобраны соответствующие образцы и проведен анализ для определения диагностических характеристик. Результаты анализа были представлены в соответствующих таблицах и были детально проанализированы. Все анализы были проведены на основе современных методов.

Ключевые слова: агроэкологическая оценка, просто буро-коричневая почва, темно буро-коричневая почва, светло буро-коричневая почва, плодородные параметры, гранулометрический состав, диагностический параметр, разрез почвы.

Цитирование. Садыгов Р. Почвенно-экологические особенности серых (каштановых) почв, образованных на северо-восточном склоне малого Кавказа (в пределах Шамкирчайского бассейна) // Природные системы и ресурсы. - 2020. - Т. 10, № 3. - C. 27-33. - DOI: https://doi.org/10.15688/nsr.jvolsu.2020.3.4

Введение. В стране осуществляются научно-исследовательские работы для проведения почвенных реформ, экономичного использования природных ресурсов, обеспечение экологических, агроэкологических, биоэкологических, геоэкологических свойств на основе мировой практики и научно-практических достижений [3; 4].

Почвенный покров считается основой природных ресурсов и промышленных сил Республики. С этой стороны самым актуальным исследованием считается изучение агроэкологических параметров, оценка развития почв с экологическим оцениванием бассейна Нового Шамкирчайского водохранилища. Шамкирчайское водохранилище является одним из двух последних водохранилищ, использованных в русле одноименной реки (Второе водохранилище называется «Тахта корпу») [1].

Почвенный покров бассейна Шамкирчайского водохранилища отличается своим сложным строением. На территории имеются несколько ландшафтных форм, свойственных государству. По географическим распределениям почвы бассейна подчиняются вертикальному зональному соответствию в свя- зи изменением высотности территории. Исследование по изучению почвенных покровов Малого Кавказа проводились М.П. Бабаевым, Г.Д. Багировым, Г.А. Гияси, Г.Ш. Мамедовым, Б.Г. Шакури, К.А. Алекперовым, В.Р. Волобуевым, М.Э. Салаевым, А.А. Ибрагимовым, А.М. Шихлинским, А.Н. Изюмовым и другими исследователями $[1 ; 2]$.

Основной целью в проведении исследования являются экологическая оценка почв бассейна, применение бонитетной шкалы, агропромышленной группировки, воздействие эрозии на диагностические показатели почв, анализирование пользы окружающей среды в развитии региона и основная цель строительства водохранилища, антропогенные и экзогенные давления, анализирование современного положения земледелия, исследования почв бассейна Нового Шамкирчайского водохранилища.

Изучение почв Нового Шамкирчайского водохранилища тесно связано с изучением геологическо-геоморфологического условия Малого Кавказа. Северо-Восточная часть Малого Кавказа имеет сложную геоморфологическую структуру. Геологическо-геоморфо- 
логическое условие Малого Кавказа было изучено М.А. Салаевым и другими исследователями. Северо-восточная часть Малого Кавказа разделяется на нижепоставленные зоны, которые сильно отличаются друг от друга по рельефу, высоте, структуре, поверхности и т. д. [2]:

1. Высокая горная зона.

2. Средняя горная зона.

3 . Низкая горная зона.

4. Пояс наклонных равнин.

Большая часть исследуемой области распространена на равнинных территориях, которые относятся к теплому климактерическому поясу, где зима проходит сухо. В нижней части бассейна климат теплый и сухой. Здесь сумма активных температур изменяется по интервалу $35-45^{\circ} \mathrm{C}$. Средняя температура июля доходит до $23^{-} 26^{\circ} \mathrm{C}$, а абсолютная максимальная температура до $37-40{ }^{\circ} \mathrm{C}$. В основном зима проникает умеренно - тепло. В бассейне январь считается самым холодным месяцем, где средняя месячная температура ближе $0{ }^{\circ} \mathrm{C}[2]$.

Влажность территории бассейна можно оценивать удовлетворительно. Количество годовых осадков составляет 240-390 мм. Зависимости от вертикального положения по мере высоты тепло снижается, и климат на высоте становится резко холодным. Снежный покров иногда продолжительно остается в некоторых частях бассейна на высоте 1300 1400 м от морского уровня.

Буро-коричневые (каштановые) почвы составляют $80 \%$ исследуемой части и находятся в сухой субтропической зоне, в области низкогорной зоны и предгорном поясе на высоте 200-300 м от морского уровня. Средняя годовая температура на территории изменяется по интервалу $10,5-14,2{ }^{\circ} \mathrm{C}$. На буро-коричневых почвах количество осадков составляет 275-440 мм.

Зависимости от условия почвообразования, от характеристик почвообразующих пород и растительных покровов в области исследование распространились в основном 3 полтипа буро-коричневых почв: темно бурокоричневые, просто буро-коричневые, светло буро-коричневые.

В сравнении с другими полутипами темно буро-коричневые почвы распростране- ны в ограниченных местах. Верхняя граница этих почв проходит по левым и правым берегам на высоте 500-550 м, а нижняя часть на высоте 200-300 м от морского уровня. Более просторные ареалы темно буро-коричневых почв подальше от оращаемых зон, изображенных в исследуемой территории.

Просто буро-коричневые почвы распространены на высоте 200-400 м в нижних частях каналов бассейна Шамкирчайского водохранилища и вокруг реки Куры. Зависимости от количества осадков и других климактерических элементов, отмеченные просто буро-коричневые почвы развиваются в условиях не обмывающего водного режима. Почвы обычно начинают кипеть с поверхности. Количество гумуса в просто буро-коричневых почвах относительно меньше, чем в темно буро-коричневых.

Светло буро-коричневые почвы распространены ниже темно буро-коричневых и просто буро-коричневых почв, где более сухо. Эти почвы охватывают нижнюю часть предгорья, правый и левый берег реки Куры и большие участки на наклонных шлейфах Шамкирского канала. Зависимости от сухого климактерического условия на территориях, где распространены светло буро-коричневые почвы процесс почвообразования происходит в необмывающем водном режиме. Эти почвы характеризуются тонким мягким профилем гумуса в сравнении с другими полутипами почв. Светло буро-коричневые почвы отличаются относительно светлым оттенком и карбонатностью.

Объект и методика исследования. Для исследования была взята территория бассейна Шамкирчайского водохранилища, находящейся на склоне Малого Кавказа. На территорию бассейна водохранилища входят некоторые части четырех регионов Республики. В результате постройки водохранилища появились орошаемые земельные участки: в районе Горанбой - 20465 га, Самух 18381 га, Гек-гел - 2300 га, Шамкир 29810 га. Объектом исследования были взяты буро-коричневые почвы, находящиеся в этих районах.

Играет большую роль применение научной методологии в прогнозировании на научных основах и определение закономерности 
научного анализа процессов, происходящих на почвах. Во время исследования были определены некоторые маршруты и на основании этого отмеченные места на поставленных разрезах почв были еще раз утверждены в степных условиях. Были прономерованы поставленные в степи почвенные разрезы, отмечены толщина почвы, гранулометрический состав, цвет, структура, твердость и ряд морфологических характеристик. Были взяты образцы по генетическим слоям, из поставленных разрезов почвы. На исследуемых материалах проводились химические анализы на основах принятых методик в лабораториях «Бонитировка и агроэкология почв» и «Мелиорация почв» Института почвоведения и агрохимии Национальной академии наук Азербайджана.

Во время степных исследований было изучено определение в степени почвенной эрозии методом С.С.Соболева и К.А. Алекперова, общего гумуса в почве методом И.М. Тюрина, общего азота методом Кейлдала, карбонатов устройством кальциметр. Основным фактором в изучении почв является гранулометрический состав, который был анализирован Н.А. Качинским. Были анализированы нитраты методом Грандал-Ляжу, растворимый в воде аммиак методом Неслера, поглощенный от форм азота аммиак методом Коньева, гигроскопическая влажность терми- ческим методом, поглощенные катионы методом Д. Иванова. Достоверность полученных результатов были уточнены методом математической статистики (Б.А. Доспрехов).

\section{Результаты и обсуждения}

В таблице 1 анализируются диагностические параметры темно буро-коричневых почв по трем разрезам. Из таблицы становится ясно, что на всех разрезах в слое толщиной 0,20 см количество гумуса изменятся по интервалу 3,97-4,36 \%. В почвенных профилях гумус постепенно распределяется до нижних слоев. На самых нижних профилях его количество составляет $1,60-0,82 \%$. Гумус аналогичен гумату и фульват гумату. Соответственно гумусу общий азот составляет $0,083-$ $0,317 \%$ (табл. 1 ).

На основе результатов анализов на поставленных разрезах темно буро-коричневых почв, было определено, что гранулометрический состав в профилях с разными фракциями ила и глины, имеет разную емкость. По профилю количество физической глины изменяется по интервалу 40,96-68,82 \%, количество фракций ила по интервалу 11,47-26,08 \%. Гигроскопическая влажность изменяется по интервалу 5,60-7,87 \%, а рН по интервалу 6,67,2 . Сумма поглощенных оснований изменяется по интервалу 22,68-32,84 мг-экв, карбонатность по интервалу 2,59-8,25 (табл. 1).

Таблица 1

Диагностические параметры темно буро-коричневых почв

\begin{tabular}{|c|c|c|c|c|c|c|c|c|c|}
\hline \multirow[t]{2}{*}{$\begin{array}{c}\text { Разрез } \\
\text { № }\end{array}$} & \multirow[t]{2}{*}{$\begin{array}{c}\text { Голубина, } \\
\text { см }\end{array}$} & \multirow[t]{2}{*}{$\begin{array}{c}\text { Гумус } \\
\%\end{array}$} & \multirow[t]{2}{*}{$\begin{array}{l}\text { Азот, } \\
\%\end{array}$} & \multirow[t]{2}{*}{$\underset{\%}{\mathrm{CaCO}_{3}}$} & \multirow[t]{2}{*}{$\begin{array}{l}\text { СПО, } \\
\text { мг-екв }\end{array}$} & \multirow{2}{*}{$\begin{array}{c}\text { Гиг. } \\
\text { влаж. } \\
\%\end{array}$} & \multirow[t]{2}{*}{$\mathrm{pH}$} & \multicolumn{2}{|c|}{$\begin{array}{c}\text { Гранулометрический } \\
\text { состав, \% }\end{array}$} \\
\hline & & & & & & & & $<0,001$ мм & $<0,01 \mathrm{MM}$ \\
\hline \multirow{5}{*}{1} & $\mathrm{AU}_{\mathrm{a}} 0-19$ & 4,13 & 0,222 & 6,95 & 22,68 & 5,83 & 6,7 & 26,08 & 65,92 \\
\hline & $\mathrm{A} / \mathrm{B} \quad 19-50$ & 2,49 & 0,212 & 7,05 & 23,12 & 6,01 & 6,7 & 21,52 & 66,48 \\
\hline & Bt $50-73$ & 2,06 & 0,204 & 7,32 & 22,72 & 6,01 & 6,6 & 24,48 & 68,82 \\
\hline & $\mathrm{B} / \mathrm{C} 73-110$ & 1,29 & 0,163 & 8,25 & 25,44 & 5,60 & 6,6 & 20,64 & 68,48 \\
\hline & C $110-155$ & 0,94 & 0,118 & 8,14 & 29,28 & 5,72 & 6,7 & 18,56 & 59,68 \\
\hline \multirow{5}{*}{2} & $\mathrm{AU}_{\mathrm{a}} 0-23$ & 3,97 & 0,218 & 3,98 & 30,78 & 6,80 & 6,8 & 18,00 & 40,97 \\
\hline & A/B 23-38 & 3,12 & 0,193 & 3,90 & 31,80 & 7,03 & 6,8 & 16,48 & 44,72 \\
\hline & Bt $38-64$ & 2,21 & 0,171 & 2,59 & 29,06 & 6,60 & 6,9 & 18,96 & 52,12 \\
\hline & B/C 64-96 & 1,06 & 0,109 & 4,25 & Не ан. & 6,69 & 6,8 & 24,80 & 46,56 \\
\hline & $\begin{array}{l}\text { C } 96-125 \\
\end{array}$ & 0,82 & 0,083 & 4,35 & - & 6,71 & 7,0 & 21,60 & 40,96 \\
\hline \multirow{5}{*}{3} & $\mathrm{AU}_{\mathrm{a}} 0-20$ & 4,36 & 0,317 & 6,97 & 28,19 & 7,87 & 7,2 & 20,16 & 55,68 \\
\hline & $\mathrm{A} / \mathrm{B} 20-39$ & 3,53 & 0,249 & 6,57 & 28,26 & 7,08 & 7,1 & 18,94 & 51,36 \\
\hline & Bt $39-60$ & 2,28 & 0,194 & 6,95 & 32,84 & 6,83 & 7,2 & 17,56 & 61,36 \\
\hline & $\mathrm{B} / \mathrm{C} \quad 60-76$ & 2,00 & 0,183 & 7,53 & Не ан. & 7,07 & 7,2 & 12,08 & 59,24 \\
\hline & C $76-98$ & 1,60 & 0,161 & 7,22 & 28,19 & 6,94 & 7,2 & 11,47 & 62,00 \\
\hline
\end{tabular}


Анализ и объяснение диагностических показателей обыкновенных серо-коричневых (каштановых) почв даны в таблице 2.

Из таблицы 2 становится ясно, что на разрезах 4, 5 и 6 в слое толщиной 0-20 см количество гумуса изменяется по интервалу $3,22-4,62 \%$, а в самом нижнем слое по интервалу $0,25-1,06 \%$. Гумус аналогичен гумату и фульват-гумату. Соотношение $\mathrm{CH} / \mathrm{Cf}$ изменяется по интервалу 1,3-1,5. Соответственно гумусу общий азот в слое толщиной 0 $20 \mathrm{~cm}$, составляет 0,236-0,323\%, соотношение $\mathrm{C} / \mathrm{N}$ изменяется по интервалу $0,7-0,9$, на самых нижних слоях составляет 0,101-0,160\% (табл. 2).

На основе анализов на поставленных разрезах 4, 5 и 6 было определено, что гранулометрический состав в профилях с разными фракциями ила и глины, имеет разную емкость, как в темно буро-коричневых почвах. Количество физической глины составляет 53,80-62,23\%, фракции ила соответственно изменяются по интервалу $16,51-$ $22,76 \%$. Гигроскопическая влажность изменяется по интервалу 2,04-4,93, а рН по интервалу $6,8-8,6$. Сумма поглощенных оснований изменяется по интервалу $25,33-$ 37,40 мг-экв, карбонатность по интервалу 7,12-12,13 (табл. 2).

В таблице 3 были анализированы диагностические параметры светло буро-коричневых почв, По результату анализов разрезов 7 ,
8 и 9 было определено, что гранулометрический состав в профилях с разными фракциями ила и глины, имеет разную емкость, По профилю количество физической глины изменяется по интервалу 53,80-66,73 \%, количество фракций ила по интервалу 11,56-23,95 \%, Гигроскопическая влажность изменяется по интервалу $2,20-4,93 \%$, а рН по интервалу 7,0-8,9. Сумма поглощенных оснований изменяется по интервалу 26,93-32,02 мг-экв, карбонатность по интервалу 8,05-17,25 (см. табл. 3).

Из таблицы 3 становится ясно, что на всех трех разрезах в слое толщиной 0-20 см количество гумуса изменяется по интервалу 1,93-2,12 \%, Распределение гумуса в почвенных профилях к нижним слоям происходит постепенно. В самых нижних профилях количество гумуса уменьшается и составляет $0,93-0,28 \%$. Гумус аналогичен гумату и фульват-гумату. Соответственно, гумусу общий азот в слое толщиной 0-20 cм, составляет $0,158-0,165 \%$. Соотношение $\mathrm{C} / \mathrm{N}$ изменяется $0,6-0,8$.

\section{Выводы}

1. Темно буро-коричневые почвы начинают кипеть с поверхности. Но на горизонтах А и А/В корбонатность бывает слабой. На изображенных почвах способность поглощения изменяется около 22-23 мг-экв. Почвенная среда бывает нейтральной или

Таблица 2

Диагностические параметры просто буро-коричневых почв

\begin{tabular}{|c|c|c|c|c|c|c|c|c|c|}
\hline \multirow[t]{2}{*}{$\begin{array}{c}\text { Разре3 } \\
\text { № }\end{array}$} & \multirow[t]{2}{*}{$\begin{array}{l}\text { Глубина, } \\
\text { см }\end{array}$} & \multirow[t]{2}{*}{$\begin{array}{c}\text { Гумус } \\
\%\end{array}$} & \multirow[t]{2}{*}{$\begin{array}{c}\text { Азот, } \\
\%\end{array}$} & \multirow[t]{2}{*}{$\begin{array}{c}\mathrm{CaCO}_{3} \\
\%\end{array}$} & \multirow[t]{2}{*}{$\begin{array}{l}\text { СПО, } \\
\text { мГ-екв }\end{array}$} & \multirow{2}{*}{$\begin{array}{c}\text { Гиг. } \\
\text { влаж. } \\
\%\end{array}$} & \multirow[t]{2}{*}{$\mathrm{pH}$} & \multicolumn{2}{|c|}{$\begin{array}{c}\text { Гранулометрический } \\
\text { состав, \% }\end{array}$} \\
\hline & & & & & & & & $<0,001 \mathrm{MM}$ & $<0,01 \mathrm{MM}$ \\
\hline \multirow{5}{*}{4} & $\mathrm{AU}_{\mathrm{a}} 0-17$ & 3,22 & 0,236 & 10,59 & 31,50 & 4,92 & 8,4 & 17,20 & 57,25 \\
\hline & $\mathrm{A} / \mathrm{B} 17-35$ & 2,81 & 0,210 & 11,25 & 30,20 & 4,45 & 8,6 & 18,62 & 55,66 \\
\hline & Bt $35-62$ & 2,01 & 0,160 & 12,13 & 28,15 & 4,84 & 8,5 & 19,04 & 61,39 \\
\hline & $\mathrm{B} / \mathrm{C} 62-85$ & 1,52 & Не ан. & 10,53 & Не ан. & 4,65 & 8,2 & 18,05 & 59,06 \\
\hline & C $85-123$ & 0,81 & - & 9,26 & - & 4,35 & 8,3 & 16,51 & 62,23 \\
\hline \multirow{5}{*}{5} & $\mathrm{AU}_{\mathrm{a}} 0-22$ & 3,35 & 0,244 & 9,65 & 27,82 & 3,78 & 8,0 & 19,00 & 59,02 \\
\hline & A/B 22-49 & 3,02 & 0,223 & 8,75 & 26,95 & 3,88 & 8,3 & 21,72 & 60,34 \\
\hline & Bt $49-63$ & 2,95 & 0,219 & 10,20 & 25,33 & 2,67 & 8,5 & 20,95 & 59,85 \\
\hline & $\mathrm{B} / \mathrm{C} \quad 63-87$ & 1,02 & Не ан. & 8,35 & Не ан. & 2,04 & 8,2 & 17,73 & 57,05 \\
\hline & C $87-119$ & 0,25 & - & 11,09 & - & 2,37 & 8,0 & 19,83 & 61,82 \\
\hline \multirow{5}{*}{6} & $\mathrm{AU}_{\mathrm{a}} 0-16$ & 4,62 & 0,323 & 7,12 & 37,40 & 4,79 & 6,8 & 20,36 & 56,72 \\
\hline & A/B 16-36 & 4,01 & 0,285 & 7,56 & 37,35 & 4,93 & 6,9 & 22,22 & 53,80 \\
\hline & Bt $36-54$ & 3,57 & 0,258 & Не ан. & 36,40 & 4,61 & 7,0 & 20,18 & 58,84 \\
\hline & $\mathrm{B} / \mathrm{C} 54-81$ & 2,42 & 0,186 & 7,68 & 36,15 & 4,48 & 6,8 & 22,76 & 60,52 \\
\hline & C $81-112$ & 1,06 & 0,101 & Не ан. & 35,78 & 4,37 & 7,1 & 21,63 & 59,73 \\
\hline
\end{tabular}


слабощелочной. По гранулометрическому составу темно буро-коричневые почвы бывают глиняные и суглинковые.

\section{2. Просто буро-коричневые почвы} бывают насыщенными основаниями и зависимо от гранулометрического состава, от количество гумуса в верхних слоях этих почв они составляют 25-35 мг-экв на каждые 100 г. Реакция почвенной среды в верхних слоях нейтральная и слабощелочная, а $\mathrm{pH}$ сохраняет нестабильность до нижних слоев.

По гранулометрическому составу эти почвы глиняные и суглинковые, на целине не наблюдается засоление просто буро-коричневых почв. Среднее количество быстрорастворимых солей не повышается выше 0,11$0,16 \%$.

\section{3. Светло буро-коричневые почвы} бывают насыщенными основаниями, как в темно буро-коричневых почвах. В верхних слоях гумус аналогичен гумату, в нижних - гумат-фульвату и фульвату. По гранулометрическому составу эти почвы глиняные и суглинковые. Реакция почвенной среды в верхних слоях слабощелочная и нейтральная.

4. Во всех трех полутипах почв, распространенных в исследуемой области гумус и минеральные вещества обеспечены средне, хорошо и относительно слабо. Эти почвы по гранулометрическому составу глиняные, суглинковые, слабощелочные, среднекарбонатные, в некоторых местах обмывающие.

\section{СПИСОК ЛИТЕРАТУРЫ}

1. Мамедов, Г. Социально-экономические и экологические основы эффективного использования почвенных ресурсов в Азербайджане / Г. Мамедов. - Баку : Элм, 2007. - 854 с.

2. Мамедов, Г. Ш. Эрозия и охрана почв / Г. Ш. Мамедов, С. З. Мамедова, Д. А. Шабанов. Баку: Элм. 2009. - 340 с.

3. Мустафаева, Н. А. Основные агроэкологические свойства почв северо-западного склона Малого Кавказа / Н. А. Мустафаева. - Баку : Наука, 2012. - C. 378-381.

4. Садыхов, Р. Влияние «Магистральных каналов» Нового Шамкирчайского водохранилища на почвенно-экологические условия бассейна / P. Садыхов // Успехи современной науки. - 2016. - Т. 11, № 12. - С. 10-13.

\section{REFERENCES}

1. Mammedov G. Sotsialno-ekonomicheskie $i$ ekologicheskie osnovy effektivnogo ispolzovaniia pochvennykh resursov $v$ Azerbaidzhane [SocioEconomic and Ecological Foundations of the Effective Use of Soil Resources in Azerbaijan]. Baku, Elm Publ., 2007. 854 p.

2. Mammedov G.S., Mammedova S.Z., Shabanov D.A. Eroziia i okhrana pochv [Erosion and Soil Protection]. Baku, Elm Publ., 2009. 340 p.

3. Mustafaeva N.A. Osnovnye agroekologicheskie svoistva pochv severozapadnogo sklona Malogo Kavkaza [Main Agroecological Properties of Soils on the Northwestern

Диагностические параметры светло буро-коричневых почв

\begin{tabular}{|c|c|c|c|c|c|c|c|c|c|}
\hline \multirow[t]{2}{*}{$\begin{array}{c}\text { Рaзpe3 } \\
\text { № }\end{array}$} & \multirow[t]{2}{*}{$\begin{array}{c}\text { Глубина, } \\
\text { см }\end{array}$} & \multirow[t]{2}{*}{$\begin{array}{c}\text { Гумус } \\
\%\end{array}$} & \multirow[t]{2}{*}{$\begin{array}{c}\text { Азот, } \\
\%\end{array}$} & \multirow[t]{2}{*}{$\begin{array}{c}\mathrm{CaCO}_{3} \\
\%\end{array}$} & \multirow[t]{2}{*}{$\begin{array}{l}\text { СПО, } \\
\text { мг-екв }\end{array}$} & \multirow{2}{*}{$\begin{array}{c}\text { Гиг, } \\
\text { влаж, } \\
\%\end{array}$} & \multirow[t]{2}{*}{$\mathrm{pH}$} & \multicolumn{2}{|c|}{$\begin{array}{c}\text { Гранулометрический } \\
\text { состав, \% } \\
\end{array}$} \\
\hline & & & & & & & & $<0,001 \mathrm{MM}$ & $<0,01 \mathrm{MM}$ \\
\hline \multirow{5}{*}{7} & $\mathrm{AU}_{\mathrm{a}} 0-17$ & 2,08 & 0,165 & 11,42 & 32,02 & 4,93 & 8,8 & 11,56 & 59,65 \\
\hline & $\mathrm{A} / \mathrm{B} \quad 17-36$ & 1,14 & 0,106 & 13,43 & 30,95 & 4,75 & 8,5 & 19,82 & 57,73 \\
\hline & $\mathrm{Bt} \quad 36-59$ & 0,87 & 0,089 & 12,52 & 28,12 & 4,85 & 8,9 & 18,75 & 60,82 \\
\hline & $\mathrm{B} / \mathrm{C} \quad 59-78$ & 0,63 & Не ан. & 17,25 & Не ан. & 4,24 & 8,3 & 20,29 & 58,61 \\
\hline & C $78-112$ & 0,28 & - & 9,11 & - & 4,68 & 8,4 & 20,73 & 61,58 \\
\hline \multirow{5}{*}{8} & $\mathrm{AU}_{\mathrm{a}} 0-18$ & 2,12 & 0,167 & 10,65 & 30,35 & 4,86 & 8,7 & 17,91 & 56,46 \\
\hline & $\mathrm{A} / \mathrm{B} \quad 18-38$ & 1,96 & 0,157 & 10,32 & 29,30 & 4,64 & 8,3 & 19,53 & 57,55 \\
\hline & Bt $\quad 38-60$ & 1,54 & 0,131 & 12,05 & 27,75 & 4,35 & 8,4 & 17,01 & 56,37 \\
\hline & $\mathrm{B} / \mathrm{C} \quad 60-83$ & 1,22 & Не ан. & 11,69 & Не ан. & 4,33 & 8,6 & 18,55 & 61,72 \\
\hline & $\begin{array}{lr}\text { C } & 83-124 \\
\end{array}$ & 0,73 & - & 9,03 & - & 4,57 & 8,5 & 19,65 & 59,95 \\
\hline \multirow{5}{*}{9} & $\mathrm{AU}_{\mathrm{a}} 0-21$ & 1,93 & 0,158 & 10,25 & 28,08 & 3,68 & 7,2 & 23,95 & 53,80 \\
\hline & A/B 21-33 & 1,46 & 0,124 & 11,72 & 27,72 & 3,82 & 7,5 & 20,82 & 57,34 \\
\hline & $\mathrm{Bt} \quad 33-75$ & 1,22 & 0,111 & 8,05 & 26,93 & 2,58 & 7,3 & 21,05 & 60,92 \\
\hline & $\mathrm{B} / \mathrm{C} 75-98$ & 1,08 & Не ан. & 9,52 & Не ан. & 2,20 & 7,1 & 23,63 & 66,73 \\
\hline & C $98-128$ & 0,93 & - & 11,85 & - & 2,76 & 7,0 & 19,24 & 63,62 \\
\hline
\end{tabular}


P. Садыгов. Почвенно-экологические особенности серых (каштановых) почв

Slope of the Lesser Caucasus]. Baku, Nauka Publ., 2012,pp. 378-381.

4. Sadykhov R. Vliianie «Magistralnykh kanalov» Novogo Shamkirchaiskogo vodokhranilishcha na pochvenno-ekologicheskie usloviia basseina
["Main Channels" Effect New Shamkirchay Reservoir on Soil and Environmental Conditions of the Basin]. Uspekhi sovremennoi nauki [Modern Science Success], 2016, vol. 11, no. 12, pp. 10-13.

\section{Information About the Author}

Ramil Sadigov, Doctor of Sciences (Agriculture), Associate Professor, Department of Petrochemical Technology and Industrial Ecology, Azerbaijan State Oil and Industry University, Prosp. Azadlig, 34, AZ1010 Baku, Republic of Azerbaijan, Ramil_Sadiqov-1983@mail.ru

\section{Информация об авторе}

Рамиль Садыгов, доктор философии по аграрным наукам, доцент кафедры нефтехимических технологий и промышленной экологии, Азербайджанский государственный нефтяной и промышленный университет, просп. Азадлыг, 34, г. Баку, AZ1010 Республика Азербайджан, Ramil_Sadiqov-1983@mail.ru 